\title{
Energy Storage Technologies for Smoothing Power Fluctuations in Marine Current Turbines
}

\author{
Zhibin Zhou, Mohamed Benbouzid, Jean Frédéric Charpentier, Franck Scuiller and Tianhao Tang
}

\begin{abstract}
With regard to marine renewable energies, significant electrical power can be extracted from marine tidal current. However, the power harnessed by a marine current turbine varies due to the periodicity of the tidal phenomenon and could be highly fluctuant caused by swell effect. To improve the power quality and make the marine current generation system more reliable, energy storage systems will play a crucial role.

In this paper, the power fluctuation phenomenon is described and the state of art of energy storage technologies is presented. Characteristics of various energy storage technologies are analyzed and compared for marine application. The comparison shows that high-energy batteries like sodiumsulphur battery and flow battery are favorable for smoothing the long-period power fluctuation due to the tide phenomenon while supercapacitors and flywheels are suitable for eliminating short-period power disturbances due to swell or turbulence phenomena. It means that hybrid storage technologies are needed for achieving optimal performance in marine current energy systems.
\end{abstract}

Index Terms-Energy storage, Marine current turbine, Power fluctuation, Battery, Flywheel, Supercapacitor.

\section{INTRODUCTION}

The main advantage of marine current energy is related to the predictability of the resource. Exploitable marine currents are mostly driven by the tidal phenomenon, which causes seawater motion twice each day with a period of approximately $12 \mathrm{~h}$ and $24 \mathrm{~min}$ (a semidiurnal tide), or once each day in about $24 \mathrm{~h}$ and $48 \mathrm{~min}$ (a diurnal tide). The astronomic nature of tides makes marine tidal currents highly predictable with 98\% accuracy for decades [1]. Marine current energy is in first order independent of season and weather conditions which would deteriorate the performances of solar and wind power generation. This characteristic is favorable for integrating marine current energy into power grid.

Z. Zhou and M.E.H. Benbouzid are with the University of Brest, EA 4325 LBMS, Rue de Kergoat, CS 93837, 29238 Brest Cedex 03, France (email: zhibin.zhou@ecole-navale.fr, Mohamed.Benbouzid@univ-brest.fr). Z. Zhou is also with the French Naval Academy and the Shanghai Maritime University.

J.F. Charpentier and F. Scuiller are with the French Naval Academy, IRENav EA 3634, 29240 Brest Cedex 9, France (e-mail: JeanFrederic.Charpentier@ecole-navale.fr, Franck.Scuiller@ecole-navale.fr).

T. Tang is with the Shanghai Maritime University, 201306 Shanghai, China (email: thtang@shmtu.edu.cn).

This work was supported by Brest Métropole Océane (BMO).
The main challenge for marine current energy system is the power fluctuation phenomenon both on short-time and long-time scales. Integration of variable and fluctuating renewable sources to power gird increases the difficulty of stabilizing the power network and balancing the supply and demand. Energy storage system (ESS) is assumed to be a good solution to smooth the power fluctuations, improve the system reliability and provide auxiliary services to the grid such as frequency regulation, energy shifting and load leveling [2-3].

In this work, the power fluctuation phenomenon in a marine current turbine (MCT) is analyzed and the state of art of the most important energy storage technologies is carried out. The ideal application environment and storage scale for each technology can be quite different; therefore the understanding of different ESS technologies and the comparisons among them can help to make a better choice for marine current energy application.

In Section II, two kinds of power fluctuation phenomena in marine current energy system are described. In Section III, battery storage technologies including conventional batteries and high-energy batteries ( $\mathrm{NaS}$ and flow batteries) are presented and compared. In Section IV, flywheel technologies are illustrated and in Section V, supercapacitor technologies are discussed. The energy storage technologies are summarized and the conclusion about suitable applications in marine current energy systems are given in Section VI.

\section{Power FluCtuAtions in MARINE CURRENT Turbines}

The power harnessed by a horizontal marine current turbine can be calculated by the following equation:

$P=\frac{1}{2} \rho C_{p} A V_{\text {tide }}^{3}$

In (1), the sea water density $\rho$ and the turbine cross area $A$ are considered as constants. For typical MCTs, $C_{p}$ is estimated to be in the range of 0.35-0.5 [4]. When a Maximal Power Point Tracking strategy is used, the turbine rotor speed is able to be controlled to keep the $C_{p}$ at its optimal value. In first order, the power produced by the MCT is proportional to the cubic of tidal current speed. It can be obviously seen from (1) that the power produced by a MCT would fluctuate severely with fluctuations in the tidal current speed.

Two main kinds of power fluctuations can be identified: on a large time scale the generated power fluctuates with a period of 6 or 12 hours which is related to tidal astronomical phenomenon; on a small time scale it would fluctuate with a 
period of a few seconds. These few seconds periods characterize long wavelength swells which affect the underwater marine current speed.

Fig. 1 gives an example of the power produced by a MCT on $24 \mathrm{~h}$ period. Fig.1a shows the long-time power variation caused by tidal astronomic nature, which is highly predictable on hourly periods. Fig.1b shows the power profile when considering swell effect, which introduces high frequency fluctuations in the power profile. This simulation is based on the tidal data provided by the SHOM (French Navy Hydrographic and Oceanographic Service, Brest, France). The $C_{p}$ is set to 0.4 and the radius of the MCT is 8 meters. The swell effect is modeled based on Stokes model and JONSWAP spectrum [5].

Fig. 2 shows the general scheme for a direct-drive MCT system integrated with ESS which aims to smooth the power produced by the turbine. Based on the turbine power profile, we can do primary requirement estimations for the ESS. The power in the ESS is equal to the difference between the

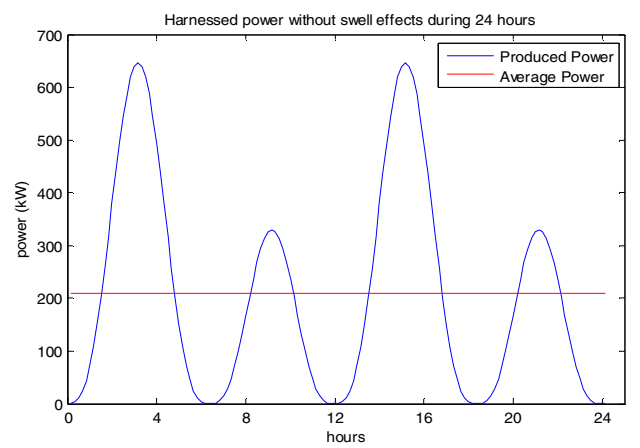

(a) without swell.

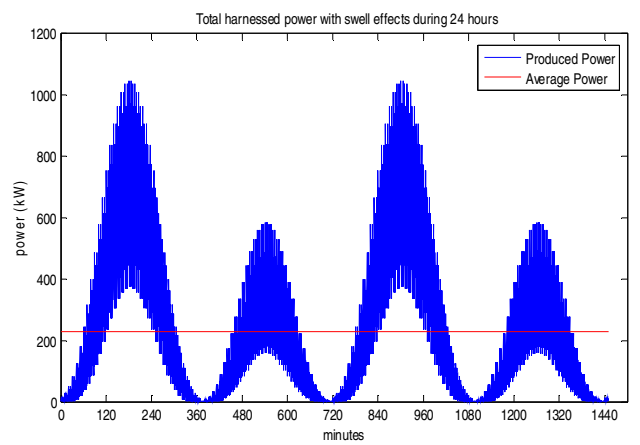

(b) with swell

Fig. 1. Power produced by a MCT for one day.

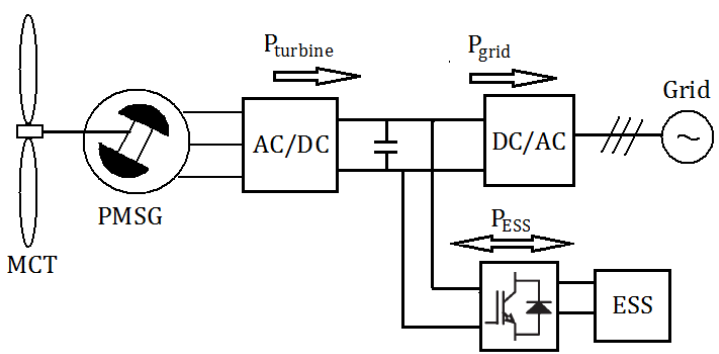

Fig. 2. General scheme for ESS integration in a PMSG-based direct-drive MCT system. turbine power and the output grid power (supposed to be the average power), and the energy in the ESS (with initial value of zero) can be calculated by:

$E_{E S S}(t)=\int_{0}^{t} P_{E S S}(t) d t=\int_{0}^{t}\left[P_{\text {turbine }}(t)-P_{\text {grid }}(t)\right] d t$

The difference between the maximum and minimum energy value calculated by (2) can serve as the energy rating estimation for the ESS. The largest difference between the produced power and the grid power can be considered as the power rating of the ESS. In the case shown in Fig. 1, for smoothing long-time power fluctuation, the required ESS is estimated with a power rating about $500 \mathrm{~kW}$ and energy rating about $800 \mathrm{kWh}$. However, the required ESS for eliminating short-time power fluctuation is estimated to have a power rating about $700 \mathrm{~kW}$ and energy rating about $2 \mathrm{kWh}$. Another point should be noticed is that the expected charge/discharge times of energy storage systems are quite different: about $3 \sim 6$ hours for long-time fluctuations and 5 20 seconds for shorttime fluctuations.

\section{BATTERY STORAGE TECHNOLOGIES}

\section{A. Lead-Acid Batteries}

Lead-acid batteries are considered as a very mature technology. They are easy to install and have a low cost. The self-discharge rate for this type of batteries is very low, around $2-5 \%$ of rated capacity per month, which makes them ideal for long-term storage applications. However, disadvantages of lead-acid batteries are low energy density and short service life. The typical energy density is around 30 $\mathrm{Wh} / \mathrm{kg}$ and the typical lifetime is between 1200 and 1800 cycles [6]. The cycle life is affected by depth of discharge and they are not suitable for discharges over $20 \%$ of their rated capacity [7]. The performance of lead-acid would also be affected by temperature: higher temperature (with the upper limit of $45^{\circ} \mathrm{C}$ ) will reduce battery lifetime and lower temperature (with the lower limit of $-5^{\circ} \mathrm{C}$ ) will reduce the efficiency.

\section{B. Nickel-Based Batteries}

There are three kinds of nickel-based batteries namely the nickel-cadmium (NiCd) battery, the nickel-metal hydride (NiMH) battery and the nickel-zinc (NiZn) battery. They have larger energy densities than lead-acid batteries: 50 $\mathrm{Wh} / \mathrm{kg}$ for $\mathrm{NiCd}, 80 \mathrm{Wh} / \mathrm{kg}$ for $\mathrm{NiMH}$ and $60 \mathrm{Wh} / \mathrm{kg}$ for NiZn.

NiCd batteries have a longer lifetime about 3000 cycles and can be fully discharged without damage. However, two drawbacks limit future large-scale deployment of this technology. One is the high price, for the NiCd battery may cost up to 10 times more than the lead-acid battery. Another is the environment concerns about cadmium toxicity and associated recycling issues [8-9].

NiMH batteries can be recycled and their components are harmless to the environment. They also can be used in large temperature ranges. However, repeatedly discharged at high 
load currents will shorten the life of NiMH batteries to about 200-300 cycles and the memory effect reduces the useful capacity of the battery. NiZn batteries share the same advantages of NiMH batteries and have deep cycle capability as NiCd batteries, but they suffer from poor life cycle due to the fast growth of dendrites.

\section{Lithium-Ion Batteries}

Lithium-ion batteries achieve excellent performances in portable electronics and medical devices. Lithium-ion batteries are lighter, smaller and more powerful than other batteries. They have the highest energy density from 90 $\mathrm{Wh} / \mathrm{kg}$ to $190 \mathrm{Wh} / \mathrm{kg}$ and the highest power density from 500 $2000 \mathrm{~W} / \mathrm{kg}$ among all the batteries [6], [8]. Other advantages include high efficiency, low memory effect and low selfdischarge rate. They are very promising to be used in nextgeneration electrical vehicles [7].

Lithium-ion batteries are theoretically characterized by a lifetime about 3000 cycles at $80 \%$ depth of discharge. In actual, lithium-ion batteries are not robust and sometimes very fragile. Life cycles are affected by temperature and would be severely shortened by deep discharges. Another drawback is that the cost of lithium-ion batteries, from $900 \$ / \mathrm{kWh}$ to $1300 \$ / \mathrm{kWh}$. These facts may limit the use of lithium-ion batteries for large-capacity applications and applications where deep discharge would be required.

\section{Sodium-Sulphur Batteries}

Sodium-sulphur (NaS) is a new promising high temperature battery technology, operating at over $300^{\circ} \mathrm{C}$. Basic cell uses liquid sulphur at the positive electrode and liquid molten sodium at the negative electrode separated by a solid beta alumina ceramic electrolyte as shown in Fig. 3.

The specific energy density of NaS battery is $100 \mathrm{Wh} / \mathrm{kg}$ and the life span is 2500 cycles at $100 \%$ depth of discharge with a high energy efficient about $89 \%$ [8]. In normal operating conditions, the heat produced by charging and discharging is enough to maintain the running temperature, but the battery still needs to be heated in stand-by mode to keep the electrodes in molten state.

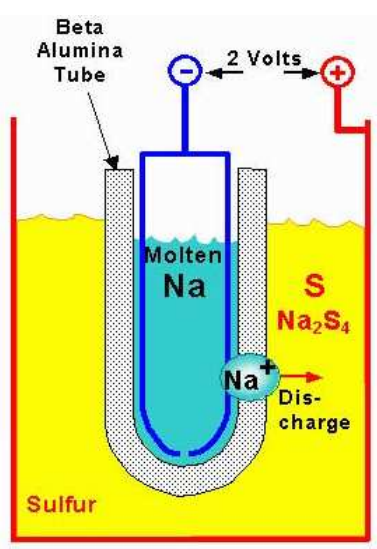

Fig. 3. Basic NaS cell [10].
To date, more than $270 \mathrm{MW}$ of total capacity has been set up at over 190 sites in Japan [10]. These batteries stored energy suitable for 6 hours of daily peak shaving. U.S. utilities have deployed $9 \mathrm{MW}$ of $\mathrm{NaS}$ batteries for reinforcing wind capacity and other applications. The largest $\mathrm{NaS}$ installation is a $34 \mathrm{MW}, 245 \mathrm{MWh}$ unit used for wind stabilization in Northern Japan.

On one hand, this technology has advantages of low cost, high energy capacity, high efficiency and deep discharge tolerance. On the other hand, this kind of battery is penalized by high operating temperature and the corrosive nature of sodium.

In the opinion of the authors, this technology appears attractive for marine renewable applications, being an effective solution for stabilizing energy output during periods of 3-6 hours in order to smooth the output of a marine current generator farm. However the operating environment must be perfectly controlled if this solution is used. This implies 'a priori' setup on an offshore platform or near the onshore transmission line for the gird.

\section{E. Flow Batteries}

Flow batteries are relatively new battery technology dedicated for large energy capacity applications. This technology consists of two electrolyte reservoirs from which the liquid electrolytes flow through an electrochemical cell comprising the electrodes and a membrane separator. Fig. 4 illustrates the structure of a flow battery system. Charging and discharging are realized by means of a reversible electrochemical reaction between two liquid electrolyte reservoirs. Flow batteries are often called redox flow batteries, based on the redox (reduction-oxidation) reaction between the two electrolytes in the system.

One distinguished advantage of flow battery technologies is that the power and energy ratings can be sized independently [9-11]. The power rating is determined by the design of the electrode cells and the energy capacity depends on the volume of the electrolytes. Therefore, flow battery can be easily designed to meet specific energy capacity or power rating requirements. These characteristics make them suitable for a wider range of applications than conventional batteries. Another significant advantage is the long service life about 10,000 cycles at $75 \%$ depth of discharge. Other advantages include high safety, negligible degradation of deep discharge and negligible self-discharge. The major disadvantage is that the flow battery system involves pump systems which increase the complexity of the total system.

Over the past 20 years, four designs of flow batteries have been demonstrated: vanadium redox (VRB), zinc bromine $(\mathrm{ZnBr})$, polysulphide bromide (PSB) and cerium zinc (CeZn). Major installations, in Japan and North American, use the $\mathrm{VRB}$ and $\mathrm{ZnBr}$ designs. VRB systems of $500 \mathrm{~kW}, 10$ hours (5MWh) have been installed in Japan by Sumitomo Electric Industries (SEI), and VRB systems have also been used for power quality applications (power supply of $3 \mathrm{MW}$ during 1.5s). $5 \mathrm{~kW} / 20 \mathrm{kWh}$ Community Energy Storage units based 


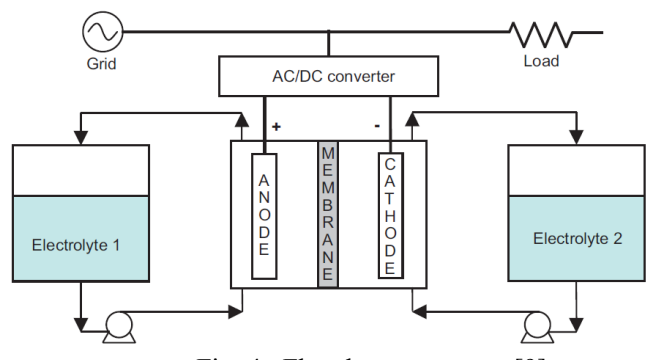

Fig. 4. Flow battery system [9].

on $\mathrm{ZnBr}$ batteries are now being tested. Integrated $\mathrm{ZnBr}$ systems have been tested on transportable trailers $(1 \mathrm{MW} / 3 \mathrm{MWh})$, and these systems could be connected in parallel for more powerful applications.

Flexible energy and power sizing, long lifetime, low cost and low maintenance make flow battery a very promising technology to be used for buffering fluctuant renewable energies integrated to the power grid. For marine current turbines, flow batteries can be designed differently for compensation short-time and long-time fluctuations, and more favorably they are suitable for hours energy storage for smoothing the fluctuation due to tidal phenomenon.

\section{F. Conclusions about Battery Technologies for Marine Application}

For marine energy application, batteries are supposed to be installed underwater or on an offshore platform. And deep discharge may be needed to achieve a required smooth effect. In the first place, low maintenance and robust long service life should be considered as important criteria; in that term the lead-acid and lithium-ion batteries are not favorable due to their short cycle life. Low cost should also be emphasized, which make lithium-ion and nickel-based batteries not attractive.

$\mathrm{NaS}$ batteries and flow batteries seem to be the two most promising candidates among other batteries. They are costeffective and have robust lifetimes. Compared with $\mathrm{NaS}$ batteries, flow batteries have a longer life span and are easier to operate; but they need a more complicated system set-up. With appropriate installations, flow batteries and $\mathrm{NaS}$ batteries suitable for smoothing the long-term fluctuation in marine energy systems.

For the short-term fluctuation (swell disturbance) with a period of seconds, a much shorter charge/discharge time is expected. The flywheel and supercapacitor technologies are presented in the following sections.

\section{FLYWHEEL TECHNOLOGIES}

A flywheel is based on a rotating disk which can store kinetic energy. This flywheel is associated with a generator/motor and drive system to control the energy storage and discharge. Low-speed flywheels (less than 10,000 $\mathrm{rpm})$ use steel rotors and have an energy density of 5$30 \mathrm{Wh} / \mathrm{kg}$. High-speed flywheels (more than 10,000 rpm) use composite rotors and low friction bearings (e.g., superconducting magnetic bearings), so they can endure extremely high rotational speed and achieve high energy density up to $100 \mathrm{Wh} / \mathrm{kg}$. The amount of energy stored in a flywheel depends on the square of the rotational speed, which makes high-speed flywheels highly desirable for energy/mass ratio optimization.

Conventional low-speed flywheels are used for the uninterruptible power supply (UPS). One of the popular flywheel UPSs is the Piller's POWERBRIDGE system available in the range of $250-1300 \mathrm{~kW}$ [12]. American company Beacon POWER is one of the leaders in the longterm (hours) application market of flywheel energy storage systems (FESS). However, recent reports show that Beacon POWER has turned to develop advanced high-power and high-energy FESS for short-term (seconds/minutes) applications [13].

Fig. 5 shows the evolution of Beacon POWER FESS products. Low-power systems (several $\mathrm{kW}$ for hours) are used for telecommunication equipment support. High-power systems (hundreds of $\mathrm{kW}$ for seconds or minutes) are used to provide power frequency regulation service for the grid.

Key advantages of flywheel technology are high cyclic ability (over $10^{5}$ cycles with deep discharge or 20 years service time), high power density (quick charge/discharge), high efficiency and low maintenance. One of the main disadvantages is the high self-discharge rate which is typically over $20 \%$ per hour. This disadvantage makes them not suitable for long-term applications. Another challenge is to reduce the high cost due to advanced materials and limited mass production.

Based on these characters, flywheels seem very appropriate for providing short-term ride-through power or smoothing the power fluctuations on a time scale of several seconds to 15 minutes. With regard to long-term energy storage, they don't have advantages over battery systems. Therefore, for marine current energy application, flywheel systems can become a very interesting candidate to compensate short-term fluctuations related to swell effects. But it seems that flywheel systems are not easy to be installed underwater considering the corrosion effects of sea water and the peripheral equipments such as power converters and transformers.

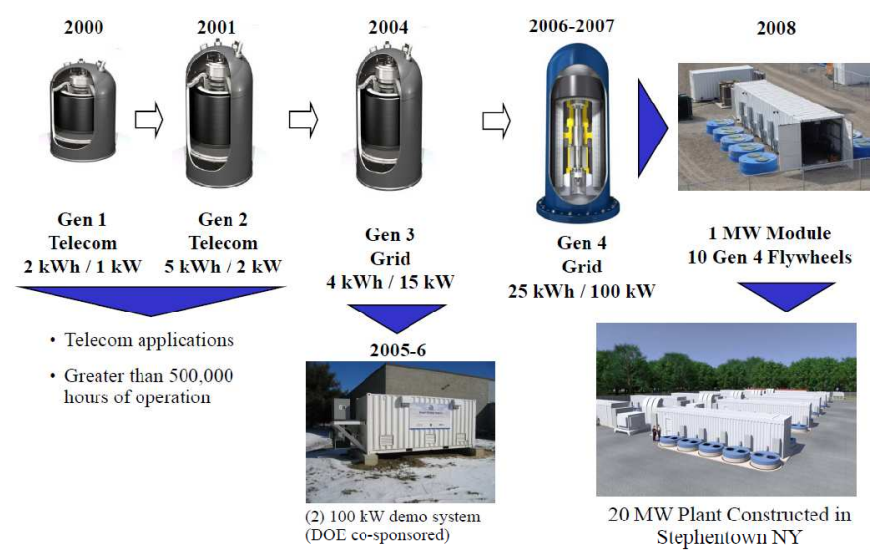

Fig. 5. Evolution of Beacon POWER Flywheel Systems [13]. 


\section{SUPERCAPACITOR TECHNOLOGIES}

Supercapacitors, also known as ultracapacitors and electrochemical double-layer capacitors (EDLCs), store energy by capacitance effect. Supercapacitors are working in a similar way as conventional capacitors, but they are characterized by a much higher capacitance (kilo farads) in smaller packages [14]. It must be remembered that the capacitance is proportional to the area of the plates and the permittivity of the dielectric; but inversely proportional to the distance between the plates. Supercapacitors use highpermittivity dielectric and maximize the electrode surface area by using porous active carbon, allowing large amount of energy to be stored at the electrode surface. The two electrodes are separated by a very thin porous separator witch is immersed in the electrolyte. The electrolyte is either aqueous or organic. The aqueous capacitors have a lower energy density due to a lower cell voltage but are less expensive. Fig. 6 shows the structure of one individual supercapacitor cell [15]. The potential difference for one cell is about $1 \mathrm{~V}$ and $3 \mathrm{~V}$ with aqueous and organic electrolyte respectively.

Thanks to that the electrodes will not be chemically degraded as in batteries, supercapacitors are able to be used during hundreds of thousands cycles in deep charge/discharge operations. Supercapacitors can be cycled more than 500,000 times and have a service life of 12 years. Power density of supercapacitors is considerably higher than batteries due to that the electrical charges are physically stored on the electrodes. Supercapacitors can be easily charged and discharged in seconds. Energy efficiency is high and no heat or hazardous substances are released during operation.

Although new materials for electrodes are being developed for increasing the energy density, supercapacitors are limited by the disadvantages of a very low energy density $(5 \mathrm{Wh} / \mathrm{kg})$ and a high self-discharge rate. That means supercapacitors can absorb or release high amount of power only during a very short time. Another point is that the lifetime of supercapacitor could be affected by the variation of voltage and by the temperature, so the design of supercapacitor system should include an aging model taking into account the operation characteristics.

One typical application for supercapacitors is hybrid electric vehicle (HEV). They can be used for energy storage from electrical braking and for providing accelerating power when needed, thanks to their fast charge and discharge capability. In a HEV, the use of supercapacitors allows

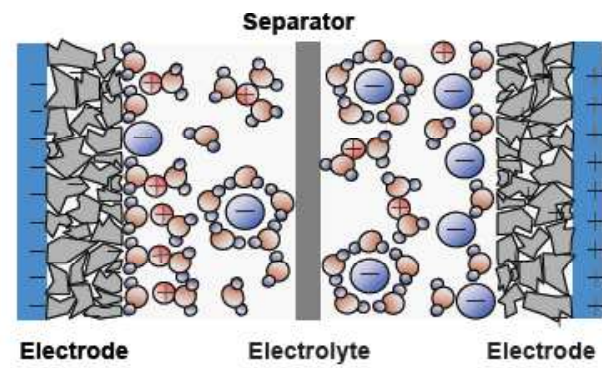

Fig. 6. Individual supercapacitor cell [15]. extending the life of the battery (by reducing battery's depth of charge/discharge) and enables the battery to be downsized (by reducing peak loads on the battery) [16]. Researches have also shown that supercapacitors can be used to absorb highfrequency power fluctuations produced from renewable energy sources. Supercapacitors for wind power application are studied in [17-20]. Supercapacitors used in photovoltaic applications are presented in [21]. In [22] a solution using supercapacitors for smoothing the power generated from SEAREV wave energy converter is presented and the State of Charge control strategy has been studied.

For marine current turbine, the supercapacitor technology appears to be one of the most appropriate solutions for smoothing the high-frequency fluctuations caused by swell effect. But supercapacitors are not suitable for smoothing the power on a time scale larger than one minute. That means high energy density and long-duration energy storage devices need to be associated with supercapacitors for obtaining a global power smooth effect in marine current application.

\section{COMPARISON AND CONCLUSION}

To be highly efficient for integrating renewable sources to power grid, storage systems should be selected carefully according to the scale of applications which are often divided into three categories based on required storage time: (1) Power Quality: charge/discharge time is required from several seconds to minutes to ensure the quality of power delivered; (2) Bridging Power: stored energy should be available from several minutes to about an hour to ensure the continuity of the power supply; (3) Energy Management: The aim of this strategy is to decouple the synchronization between power generation and consumption. This application requires large quantity of energy stored for several hours.

Fig. 7 summarizes and compares energy storage systems based on power ratings, discharge times and different applications. The interesting ranges for smoothing long-time power fluctuation related to tidal phenomenon and short-time fluctuation caused by swell effect have been highlighted. From Fig. 7, we can see that pumped hydro (PHS) and compressed air energy storage system (CAES) seem too large for marine current energy application. That is the reason these

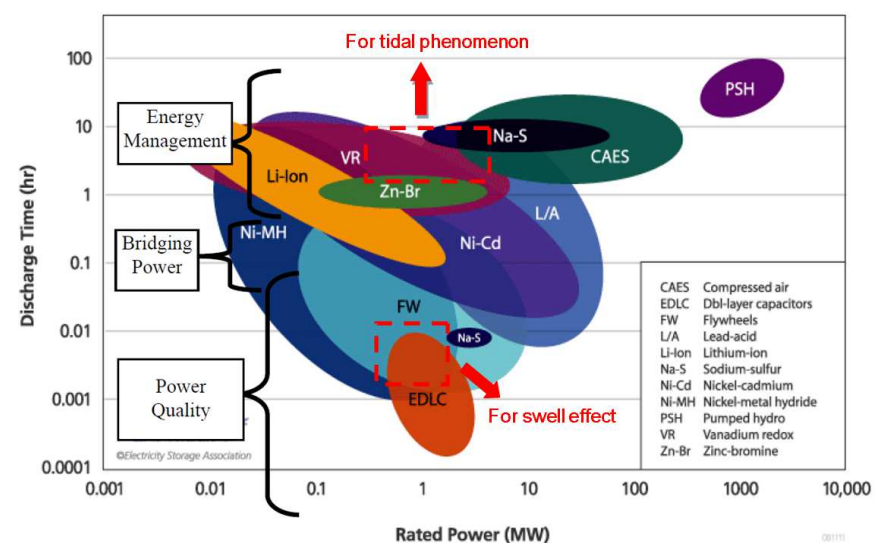

Fig. 7. Summarizing of energy storage technologies [23]. 


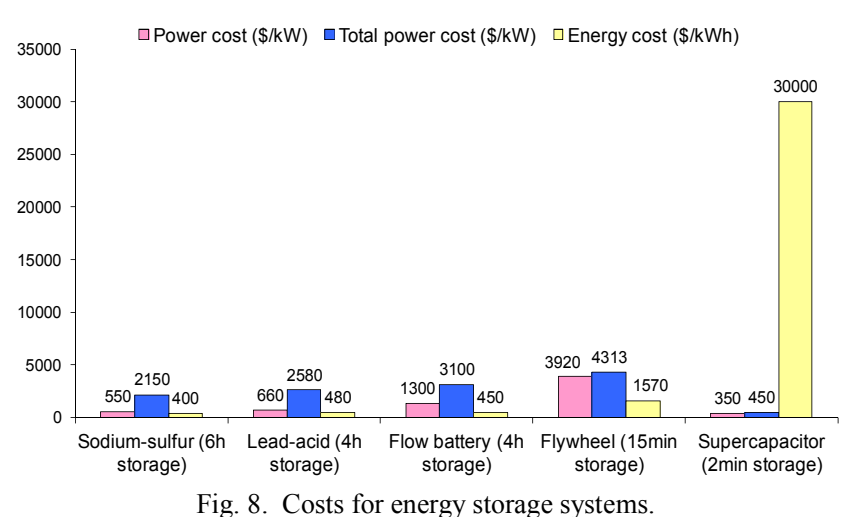

two technologies are not discussed in this paper. We can also see from Fig. 7 that various technologies can be applied for some same application. In that case, cost may become a decisive factor for choosing the final solution. Fig. 8 (data from [24]) illustrates the costs of different energy storage systems. The total power cost includes necessary power converter and equipment for regulating the energy storage device.

Based on characteristics for each presented energy storage technology, and from Fig. 7 and Fig. 8, we can see that for smoothing the long-time (3 6 hours) power fluctuation in the marine current generation system, high-energy batteries like flow batteries and NaS batteries can be a good solution. They can also perform energy management strategies for a marine current turbine farm.

With regard to short-term energy storage (seconds to minutes) for compensating the power fluctuation caused by swell effect, supercapacitor and flywheel technologies are the best candidates due to their fast charge/discharge capabilities and long cycle life. It should be noticed that flywheel have a higher power cost than supercapacitor due to higher power rating and higher energy capacity. Supercapacitor can be integrated to the dc-link of the converter system for marine current turbine, so they are appropriate for one generation unit. Flywheel systems are suitable for land-installation near the grid transmission line, therefore they seem more favorable for a farm of marine current turbines.

\section{REFERENCES}

[1] S. Benelghali, R. Balme, K. Le Saux, M. E. H. Benbouzid, J. F. Charpentier, and F. Hauville, "A simulation model for the evaluation of the electrical power potential harnessed by a marine current turbine," IEEE Journal of Oceanic Engineering, vol. 32, no.4, pp.786-797, Oct. 2007.

[2] H. Ibrahim, A. Ilinca, J. Perron, "Energy storage systemsCharacteristics and comparisons," Renewable and Sustainable Energy Reviews, vol. 12, pp.1221-1250, 2008.

[3] S. Vazquez, S. M. Lukic, E. Galvan, L. G. Franquelo, and J. M. Carrasco, "Energy storage systems for transport and grid applications," IEEE Trans. Ind. Electron., vol. 57, no.12, pp.3881-3895, Dec. 2010.

[4] S. Benelghali, M. E. H. Benbouzid, T. Ahmed-Ali, and J. F. Charpentier, "High-order sliding mode control of a marine current turbine driven doubly-fed induction generator," IEEE Journal of Oceanic Engineering, vol. 35, no.2, pp.402-411, Apr. 2010.
[5] Y. Goda, "Random Seas and Design of Maritime Structures," 3rd edition, Advanced Series on Ocean Engineering, vol.33, World Scientific, Singapore, 2010.

[6] I. Hadjipaschalis, A. Poullikkas, and V. Efthimiou, "Overview of current and future energy storage technologies for electric power applications," Renewable and Sustainable Energy Reviews, vol. 13, pp.1513-1522, 2009.

[7] A. Khaligh and Z. Li, "Battery, ultracapacitor, fuel cell, and hybrid energy storage systems for electric, hybrid electric, fuel cell, and plugin hybrid electric vehicles: State of the art," IEEE Trans.Veh.Technol, vol. 59, no.6, pp.2806-2814, Jul. 2010.

[8] K.C. Divya and J. Østergaard, "Battery energy storage technology for power systems-An overview," Electric Power Systems Research, vol. 79, pp.511-520, 2009.

[9] J. Baker, "New technology and possible advances in energy storage," Energy Policy, vol. 36, pp.4368-4373, 2008.

[10] http://www.electricitystorage.org/technology/storage_technologies/ (last accessed Aug. 2011)

[11] P. J. Hall and E. J. Bain, "Energy-storage technologies and electricity generation," Energy Policy, vol. 36, pp.4352-4355, 2008.

[12] G. O. Cimuca, C. Saudemont, B. Robyns, and M. M. Radulescu, "Control and performance evaluation of a flywheel energy-storage system associated to a variable-speed wind generator," IEEE Trans. Ind. Electron., vol. 53, no.4, pp.1047-1085, Aug. 2006.

[13] http://www.beaconpower.com/products/presentations-reports.asp (last accessed Aug. 2011)

[14] S. Vazquez, S. M. Lukic, E. Galvan, L. G. Franquelo, and J. M. Carrasco, "Energy storage systems for transport and grid applications," IEEE Trans. Ind. Electron., vol. 57, no.12, pp.3881-3895, Dec. 2010.

[15] W. Chen, A. K. Ådnanses, J. F. Hansen, J. O. Lindtjørn, and T.Tang, "Super-capacitors based hybrid converter in marine electric propulsion system," in Proc. IEEE XIX Int. Electr. Mach. Conf., Rome, pp.1-6, Sep. 2010.

[16] P. Thounthong, V. Chunkag, P. Sethakul, B. Davat, and M. Hinaje, "Comparative study of fuel-cell vehicle hybridization with battery or supercapacitor storage device," IEEE Trans. Veh. Technol., vol. 58, no.8, pp.3892-3904, Oct. 2009.

[17] C. Abbey and G. Joos, "Supercapacitor energy storage for wind energy applications," IEEE Trans. Ind. Appl., vol. 43, no.3, pp.769-776, May/Jun. 2007.

[18] L. Qu and W. Qiao, "Constant power control of DFIG wind turbines with supercapacitor energy storage," IEEE Trans. Ind. Appl., vol. 47, no.1, pp.359-367, Jan./Feb. 2011.

[19] W. Li, G. Joós, and J. Bélanger, "Real-time simulation of a wind turbine generator coupled with a battery supercapacitor energy storage system," IEEE Trans. Ind. Electron., vol. 57, no.4, pp.1137-1145, Apr. 2010.

[20] H. Jia, Y. Fu, Y. Zhang, and W. He, "Design of hybrid energy storage control system for wind farms based on flow battery and electric double-layer capacitor," in Proc. IEEE Power and Energy Eng. Conf., Asia-Pacific, pp.1-6, Mar. 2010.

[21] Y. Cheng, "Super Capacitor Applications for Renewable Energy Generation and Control in Smart Grids," in Proc. IEEE International Symposium on Ind.Elecron.,pp.1131-1136, Jun. 2011.

[22] J. Aubry, P. Bydlowski, B. Multon, H. Ben Ahmed, and B. Borgarino, "Energy storage system sizing for smoothing power generation of direct wave energy converters," in Proc. 3rd Int. Ocean Energy Conf., Bilbao, Spain, Oct. 2010.

[23] P. Denholm, E. Ela, B. Kirby, and M. Milligan, "The role of energy storage with renewable electricity generation," Technical Report of National Renewable Energy Laboratory, U.S., Jan. 2010 (http://www.nrel.gov/wind/systemsintegration/pdfs/2010/ela_energy_st orage.pdf )

[24] D. Raster, "New demand for energy storage," Electric Perspectives, pp.30-47, Sep./Oct. 2008. 